\title{
Trophy quality trends and hunting effort of selected big game in Chewore South Safari Area, northern Zimbabwe, 2009-2012
}

\author{
Never Muboko ${ }^{1} \cdot$ Pardon Dube $^{1} \cdot$ Clayton Mashapa $^{1}\left[\right.$ Edmore Ngosi $^{2} \cdot$ Edson Gandiwa $^{1}$
}

Received: 10 July 2019 / Revised: 18 September 2020 / Accepted: 5 November 2020 / Published online: 23 November 2020

(c) International Society for Tropical Ecology 2020

\begin{abstract}
This study was based on a temporal analysis of trophy quality trends and hunting effort in Chewore South Safari Area (CSSA), Zimbabwe, for the period 2009-2012. We selected four of the big five species, namely; buffalo (Syncerus caffer), elephant (Loxodonta africana), the leopard (Panthera pardus) and lion (Panthera leo) for analysis. Existing database of 188 trophies from 2009 to 2011 was reviewed and recorded using the Safari Club International (SCI) scoring system. Further, 50 trophies for 2012 were measured and recorded based on the SCI scoring system. Local ecological knowledge on trophy quality and hunting effort in CSSA was obtained through semi-structured questionnaires from 22 conveniently selected professional hunters in 2012. The results indicated no significant change in trophy quality trends of buffalo, leopard and lion $(p>0.05)$ over the study period. In contrast, there was a significant decline in elephant trophy quality trend over the same period $(p<0.05)$. The results showed no significant change in hunting effort over the study period for all the four study species $(p>0.05)$. Furthermore, seventy-two percent $(72 \%, n=13)$ of the professional hunters confirmed that elephant population was declining in CSSA and this was likely due to poaching. Professional hunters perceived trophy hunting as a source of financial capital generation for wildlife conservation $(61 \%, n=11)$, as well as positively contributing to the local economy $(56 \%, n=10)$. It was concluded that hunting has limited negative impact on species trophy quality trends when a sustainable hunting system is consistently followed in CSSA. CSSA management need to continuously monitor trophy hunting, animal populations and employ adaptive management approach to quota setting and species conservation.
\end{abstract}

Keywords Big game $\cdot$ Hunting effort $\cdot$ Local ecological knowledge $\cdot$ Trophy quality

\section{Introduction}

Hunting is the practice of pursuing any living thing, usually wild animals, by humans for food, recreation, or trade (Hsiao 2020). This is an ancient activity, dating back thousands of years where hunting methods included the use of spears, large rocks, or running the animal over a cliff (Puertas et al. 2004; Gandiwa et al. 2014a). Hunting has varied but often overlapping motives which can be based on economic, ecological, social and self-centred interests (Croes et al. 2011; Dube 2019). For example, economic and ecological motives

Clayton Mashapa

clayiemashapa@yahoo.co.uk

1 Department of Wildlife Ecology and Conservation, Chinhoyi University of Technology, Private Bag 7724, Chinhoyi, Zimbabwe

2 Zimbabwe Parks and Wildlife Management Authority, c/o P. Bag 7713, Mkanga Field Station, Chinhoyi, Zimbabwe aim to raise revenue that can be re-invested into conservation (Damm 2008; Saayman et al. 2018), while activities like problem animal control (PAC) can have a social motive where problem animals attacking people or destroying people's properties may be hunted to address social concerns and improve public relations (Balme et al. 2010; MhuriroMashapa et al. 2018). However, today the term 'hunting' is historically and commonly associated with the trophy hunting of Africa's big five, also referred to as the "big game" (IUCN 2012), i.e., the buffalo (Syncerus caffer), elephant (Loxodonta africana), leopard (Panthera pardus), lion (Panthera leo) and the two rhinoceros species, i.e., black rhino (Diceros bicornis) and white rhino (Ceratotherium simum). Trophy hunting, if based on scientifically designed and managed programs, can provide various socioeconomic and ecological benefits at the local, national, regional and global levels. However, trophy hunting has emerged as a debatable and contested issue in the world due to its profound sociopolitical and ecological consequences (Hsiao 2020). 
According to Croes et al. (2011), a trophy is any durable part of a hunted animal and hunters usually prefer the skulls and skins of the hunted wild animals. Trophy hunting is highly selective as it targets the limited preferred species as informed by the set hunting quotas for the targeted animals in a population with outstanding characteristics, such as horns, tusks, body size and skull length. This is distinguished from predation where the predator targets the weakest individual in the prey population (Bothma and Bothma 2006; Lindsey et al. 2006; Rivrud et al. 2013) hypothesised that trophy hunters will consistently target good quality prime-aged individual wild animals, therefore the young or weaker adults will have the responsibility to reproduce. Hence, although sport hunting plays an important role in the dynamics of ungulate populations, it can result in increased mortality and reduced life expectancy, with older animals becoming rare (Damm 2008; Funston 2011; Batavia et al. 2019). Thus, heredity and good animal traits can be lost, and this has adverse effects on body sizes and evolutionary development (Mysterud 2011).

It follows that when poorly managed, trophy hunting can cause negative ecological impacts for the target species including population declines in the event of excessive off-take, threatening conservation efforts and even influencing the behavior of non-target species (Hsiao 2020). In sub-Saharan Africa there has been a noted decline of trophy quality of the hunted big game, resulting in some countries like Kenya banning trophy hunting from 1977 to date (Caro and Andimile 2009). However, despite the ecological and economic concerns over trophy hunting, it is a recreational activity or sport in high demand in the African tourism landscape, where most tourists come for trophy hunting (Lindsey et al. 2006; Saayman et al. 2018). Thus, the hunting pressure has been constantly increasing as the market for trophy hunting grows. Trophy hunting is practiced legally in 23 sub-Sahara African countries, and was recorded to generate at least US\$ 201 million per year from more or less 18,500 international hunting clients (Lindsey et al. 2006; Groom and Harris 2009; Crosmary et al. 2013), that is before the not yet quantified effects of the novel coronavirus (Covid19) pandemic.

Research has also shown that trophy hunting creates incentives for the conservation of wild animal species and the sustainable management of protected area ecosystems (Lindsey et al. 2006; Mposhi et al. 2016). It is hence considered a market-based intervention to conservation in most countries endowed with diverse wildlife resources (Naidoo et al. 2016). Trophy hunting as a form of sustainable land use is a strong economic instrument that apart from incentivizing conservation also contributes to rural development through integrated conservation and development projects (ICDP), especially in most tropical countries (Frost and Bond 2008). For example, in Zimbabwe, the trophy hunting industry grew rapidly upon its introduction in the 1980s in marginalized and vulnerable communities under the Communal Area Management Programme for Indigenous Resources (CAMPFIRE) (Gandiwa et al. 2013; Muboko and Murindagomo 2014). This sustainable land use concept associated with trophy hunting is supported by the Convention on Biological Diversity (CBD) which considers conservation to be largely characterized by sustainable utilization of resources for rural development (MacDonald 2005).

The growth of trophy hunting industry has been anchored on four species of the big five, except for the rhino species, as they lure more than $90 \%$ of the hunters in Africa (Lindsey 2010). Trophy hunting is regulated by a quota system to ensure maintenance of trophy quality and provide a scientific basis for animal off-take. The quota system is also meant to balance commercialisation and conservation of wildlife as it acts as a credible conduit for hunting and trophy monitoring (Chomba et al. 2014). Thus, trophy hunting can be used to control animal populations. This is consistent with most wildlife ecologists' views that trophy quality and catch per unit effort (CPUE) are major indicators for sustainability in trophy hunting and conservation (Wilfred 2010; Crosmary et al. 2013). When hunting pressure is high the animals tend to be more vigilant thus the hunting effort increases (Wilfred 2010). A decline in trophy quality is assumed to indicate over harvesting and or other factors related to environmental degradation, for example, nutritional deficiency when forage is limited resulting in restrained animal growth (Crosmary et al. 2013). Also, other factors include contest intra- and inter-specific competition which results in reduced body sizes due to shrinking home ranges and less forage as influenced by climate variability (Ramanzin and Sturaro 2014). In such cases, it becomes unsustainable to continue harvesting as trophy quality is not only poor, but targeted populations can be driven to human-induced extinctions (Coulson et al. 2017).

Balancing commercialisation and conservation is often easier said than done, especially where there are other intervening elements. It is thought that Zimbabwe's economic challenges which began in 2000 caused a rise in hunting quota allocation based on unproven population guestimates as managers tried to increase profits from trophy hunting (Muposhi et al. 2016). The current criticisms on the lack of valid scientific and economic data regarding the sustainability of trophy hunting in Zimbabwe provides ammunition to wild animal rights movements in their attempt to completely restrict the trophy hunting industry. Furthermore, international bodies such as the Convention on International Trade in Endangered Species of Wild Flora and Fauna (CITES) are constantly being pressured to impose restrictions on the industry based on issues such as poor monitoring and regulation of trophy hunting. In the case of CSSA, information on the trophy size-based quality trends and hunting effort for 
the four selected big game species is not readily available, while most literature focuses mainly on marketing CSSA as a hunting destination (ZPWMA 2013). Hence, this study aimed to establish whether the current hunting systems in CSSA are sustainable by analysing the trophy quality patterns and hunting effort for the buffalo, elephant, leopard and lion from 2009 to 2012. Specifically, the objectives of the study were three fold and all based on the selected four of the big five species in CSSA: (1) to determine the trophy quality patterns of buffalo, elephant, leopard and lion in CSSA from 2009 to 2012; (2) to determine the changes in hunting effort on the targeted four species, and (3) to determine professional hunters' perceptions on trophy quality and hunting effort of the four big game species in CSSA.

\section{Materials and methods}

\section{Study area}

Chewore South Safari Area (CSSA) is located within the Zambezi Valley, northern Zimbabwe, and lies between $15^{\circ} 37^{\prime}$ to $16^{\circ} 25^{\prime} \mathrm{S}$ and $29^{\circ} 08^{\prime}$ to $30^{\circ} 20^{\prime} \mathrm{E}$ (Fig. 1). Part of CSSA constitute a wilderness area that was declared a United Nations Educational, Scientific and Cultural Organisation (UNESCO) World Heritage Site in 1984 because of its outstanding natural ecosystem and its magnificent ecological (hot-spot of biodiversity) and human cultural qualities (Hyde et al. 2015). CSSA experiences the wet season from November to April and has an average annual rainfall of $730 \mathrm{~mm}$ (Hyde et al. 2015). Mean annual temperature ranges from 17 to $33{ }^{\circ} \mathrm{C}$ (ZPWMA 2013). CSSA is dominated by vast expanses of Mopani (Colophospermum mopane) woodlands and dry deciduous thickets known as 'jesse bush'. The vegetation types consist of mixed Miombo and Brachystegia species woodlands (Dunham 1991; Hyde et al. 2015).

Trophy hunting is seasonal in CSSA, taking place between May and September of each year. The present study focused on four species of the 'big five' and excludes the rhinos whose hunting is prohibited in Zimbabwe (IUCN 2012). The densities of the study species in the study area have been documented by Kuvawoga and Gandiwa (2011) and Grant (2012) as: buffalo (0.7 individuals per $\left.\mathrm{km}^{2}\right)$, elephant (1.5 individuals per $\left.\mathrm{km}^{2}\right)$, lion $\left(0.01\right.$ individuals per $\left.\mathrm{km}^{2}\right)$ and leopard (0.1 individuals per $\mathrm{km}^{2}$ ) for the period 2010-2011. During this same period, the average harvest rates (i.e., number of individuals harvested per year divided by the total population estimate for that year (ZPWMA 2013) was $1.8 \pm 1.2 \%$ for the four species. Hunted wild animals and trophy export record from CSSA indicated that importing countries were mainly from North America, Europe, Africa and Asia (ZPWMA 2013).

\section{Data collection}

Documentary review and participatory research designs were employed following the methods by Wilfred (2010) and Crosmary et al. (2013). Records on trophy size, quota allocations and utilization levels for the selected four big game species were readily available for the period 2009-2012 at CSSA headquarters in their raw form. Quantitative data was obtained from historical records obtained from the Zimbabwe Parks and Wildlife Management Authority (ZPWMA) database (ZPWMA 2013). The quantitative data addressed the research questions on trophy quality patterns and hunting effort. The qualitative data was obtained through administering semi-structured questionnaires. Semi-structured questionnaires were self-administered to conveniently selected 22 professional hunters to collect data on trophy quality and hunting effort in CSSA. The selected professional hunters collected the semi-structured questionnaire at the start of each hunt. The semi-structured questionnaires were administered during the 2012 dry season (May-August). Out of the 22 semi-structured questionnaires administered to the professional hunters, about $82 \%(n=18)$ were responded to. The average experience in the hunting industry ranged from 6 to 25 years and more than $78 \%(n=17)$ of the respondents had above 5 years' experience in CSSA. A four-year period of study was selected, i.e., 2009-2012 due to lack of longterm historical data.

\section{Trophy measurements and hunting effort determination}

A total of 188 existing trophies were measured and verified using the Safari Club International (SCI) measuring standards (Crossmary et al. 2013). For instance, the minimum score of the buffalo horns should be 100 inches, whereas, the weight of elephant tusks and the minimum score should be 90 pounds as stated by the SCI (1988). For lions and leopards, the length of the trophy (skull) was measured and the SCI minimum score for the lion is 23 inches and 14 inches for leopards (SCI 1988).

The trophy quality index was determined to find whether the actual measurements exceed the minimum standard in order to deduce the sustainability of the harvesting. If the index is $(\mu=<1)$ it indicates poor trophy quality and unsustainable hunting following von Brandis and Reilly (2008), i.e., index $=$ individual observation / standard trophy quality (SCI). For hunting effort, i.e., Catch Per Unit Effort, was determined using the time taken in days to pursue and kill the targeted animal in a trophy hunt (Rist et al. 2010). Variables considered where the date of starting the safari hunt, the purpose of the hunt, the date and species killed, and these were retrieved from the CSSA records for each hunt to determine the effort in days. 
Fig. 1 Location of Chewore South Safari Area (CSSA), northern Zimbabwe. Notes: the shaded area indicates both Chewore North and Chewore South, and the study site CSSA is indicated by a dotted circle

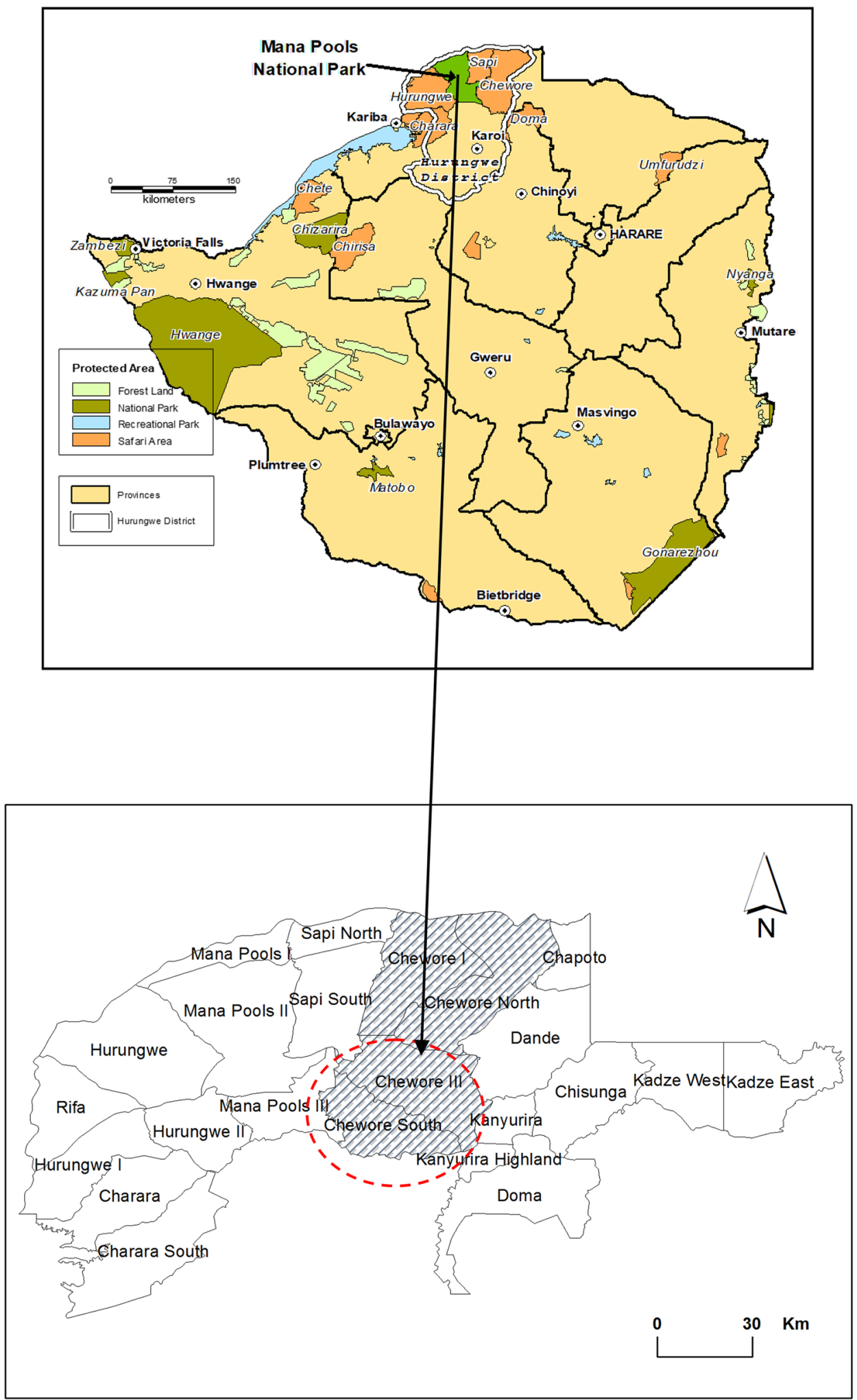

\section{Data analysis}

A regression analysis was used to analyse trends in trophy size across the study species and over years following von
Brandis and Reilly (2008). Trophy size value of each of the recorded four big game species was divided by the respective minimum trophy size required to determine the hunting effort and quota set to ensure sustainable 
off-take (Jeke et al. 2019). We expressed the total number of harvested individuals for each of the four big species per given year from the corresponding allocated quota as percentage quota utilization using the formula: (Hunting success $=[$ Total harvested/Total quota $] \times 100)($ Jeke et al. 2019). A one-way analysis of variance (ANOVA) was used to determine the variation in hunting effort for each species over the years in STATISTICA version 10 for Windows (StatSoft 2010). Data from the 18 semi-structured questionnaires were analyzed by way of thematic coding. Codes (words or phrases representing a single idea) were identified and, based on critical reading of the transcribed interviews, allocated into broader themes (Aronson 1995). The emergent themes were analyzed by finding patterns within the data that related to professional hunters' perceptions on trophy quality and hunting effort of four of the big five species in CSSA.
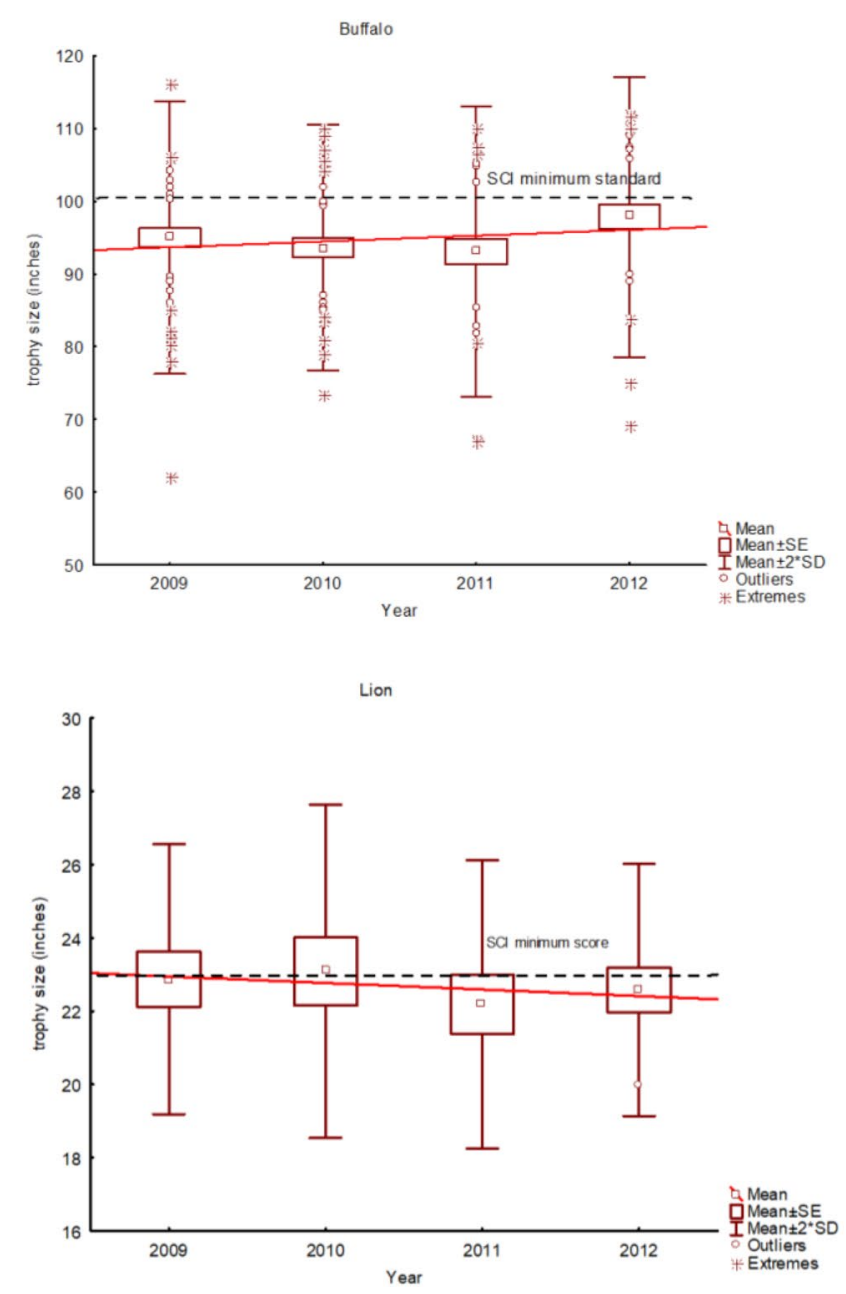

\section{Results}

\section{Trophy size trends for the four selected big game species in CSSA, 2009-2012}

Our results indicate that the trophy sizes of the buffalo where below the SCI minimum standard quality of 100 inches, and there was no significant change recorded in buffalo trophy size trend over the four years from 2009 to $2012(\beta=0.08, t=0.98$, $p>0.05$; Fig. 2). The mean trophy size of leopard was above the SCI minimum standard score of 14 inches, and no significant change in leopard trophy size trend over the period was observed $(\beta=-0.81, t=-0.37, p>0.05)$. Results showed that the mean quality of lion trophy size was below the SCI minimum standard score of 23 inches, with no significant change in the lion trophy size from 2009 to $2012(\beta=-0.10$, $t=-0.51, p>0.05)$. In contrast, the elephant trophy sizes were below the SCI minimum trophy size score of 90 pounds
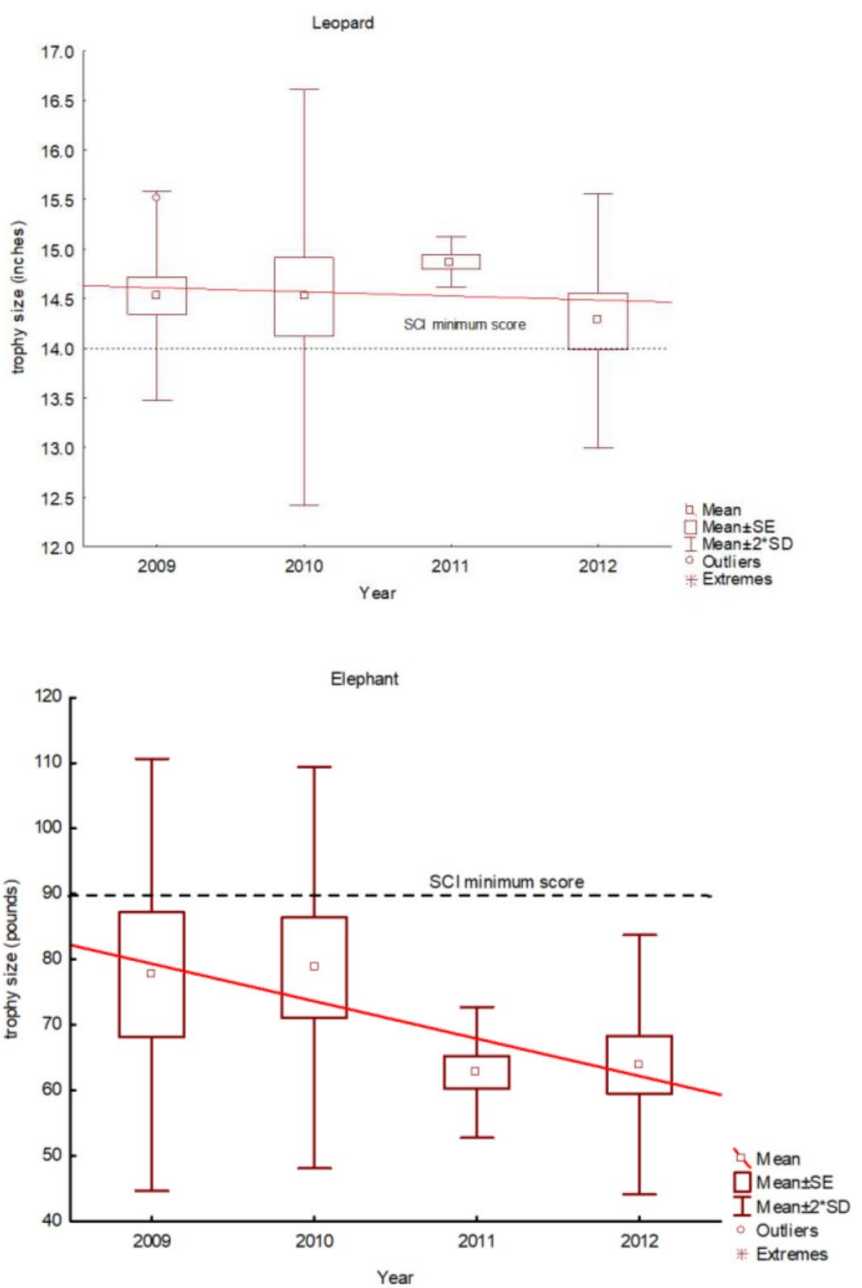

Fig. 2 Trophy size quality trends for the four study species in Chewore South Safari Area, 2009-2012 
Table 1 Offtake, hunting success and trophy quality for the four selected big game species in CSSA, 2009-2012

\begin{tabular}{lcllll}
\hline Species & Offtake & $\begin{array}{l}\text { Hunting suc- } \\
\text { cess }(\%)\end{array}$ & $\begin{array}{l}\text { SCI Standard } \\
\text { trophy size }\end{array}$ & Mean trophy size & $\begin{array}{l}\text { Mean quality } \\
\text { index } \pm \text { SE }\end{array}$ \\
\hline Elephant & 16 & 100 & 90 pounds & 69.92 pounds & $0.78 \pm 0.03$ \\
Buffalo & 158 & 100 & 100 inches & 94.86 inches & $0.95 \pm 0.60$ \\
Lion & 26 & 100 & 23 inches & 22.67 inches & $0.98 \pm 0.01$ \\
Leopard & 23 & 79 & 14 inches & 14.52 inches & $1.04 \pm 0.01$ \\
\hline
\end{tabular}

Table 2 Hunting effort in CSSA, 2009-2012

\begin{tabular}{|c|c|c|c|c|c|c|}
\hline \multirow[t]{2}{*}{ Species } & \multicolumn{4}{|l|}{ Years } & \multicolumn{2}{|c|}{ ANOVA statistics } \\
\hline & 2009 & 2010 & 2011 & 2012 & $F$ value & $p$ value \\
\hline Elephant & $7.50 \pm 2.80$ & $5.50 \pm 0.73$ & $7.80 \pm 1.80$ & $9.50 \pm 0.50$ & 1.00 & 0.420 \\
\hline Buffalo & $5.90 \pm 0.59$ & $5.00 \pm 0.56$ & $5.16 \pm 0.61$ & $4.15 \pm 0.54$ & 1.55 & 0.203 \\
\hline Lion & $10.00 \pm 3.89$ & $6.40 \pm 1.54$ & $6.80 \pm 1.64$ & $5.80 \pm 1.55$ & 0.75 & 0.534 \\
\hline Leopard & $10.30 \pm 2.65$ & $10.60 \pm 2.83$ & $7.00 \pm 1.73$ & $6.00 \pm 2.24$ & 2.16 & 0.127 \\
\hline
\end{tabular}

ANOVA results show hunting effort in days for the four study species (mean hunting effort \pm SE) and showed a significant decline in elephant trophy sizes over the period under study $(\beta=-0.50, t=-2.15, p<0.05)$.

\section{Trophy size-based quality index and hunting effort for the four selected big game species in CSSA, 2009-2012}

A total hunting quota of 238 for the four study species was allocated to safari operators with 223 male individuals having been hunted between 2009 and 2012. Leopard had the greatest mean size-based quality index $($ mean $=1.04 \pm 0.01)$ whereas the other three species, i.e., elephant, buffalo and lion had lower quality indices (Table 1). Study results showed that there was no significant difference in hunting effort for all the study species over the study period (all, $p>0.05$; Table 2 ).

\section{Professional hunters' perception on trophy hunting of the four selected big game species in CSSA}

Seventy-two percent $(72 \%, n=13)$ of the professional hunters confirmed that elephant population was declining in CSSA and this was likely due to poaching rather than trophy hunting (Table 3). The professional hunters highlighted elephant poaching as a concern to be rectified as it was compromising the trophy quality of elephants. Professional hunters perceived trophy hunting as a financial capital generation activity for wildlife conservation $(61 \%, n=11)$, as well as contributing to the local economy $(56 \%, n=10)$.
Table 3 Professional hunters' response on trophy quality and hunting effort in Chewore South Safari Area, 2009-2012

\begin{tabular}{lll}
\hline Response item & $\begin{array}{l}\text { Responses } \\
(n=18)\end{array}$ & $\begin{array}{l}\text { Per- } \\
\text { centage } \\
(\%)\end{array}$ \\
\hline $\begin{array}{l}\text { Elephant population declining due to poaching } \\
\begin{array}{l}\text { Trophy hunting generate funds for conserva- } \\
\text { tion }\end{array}\end{array}$ & 13 & 72 \\
Positive economic impact of trophy hunting & 10 & 61 \\
High hunting pressure & 7 & 36 \\
High buffalo quota & 6 & 33 \\
High lioness population & 6 & 33 \\
Human disturbance on wildlife habitat & 5 & 28 \\
Consider including lioness on quota & 4 & 22 \\
High lion quota & 2 & 11 \\
Hunting fatigue due high hunting effort & 1 & 6 \\
\hline
\end{tabular}

\section{Discussion}

The study revealed trophy quality decline in one of the four study species, namely elephant. Poaching was largely attributed to elephant trophy quality decline in the CSSA. Poaching leads to unplanned offtake since animals will be killed illegally irrespective of the allocated quota (Lindsey 
et al. 2006). Similar observations were made by Nuzzo and Traill (2013) who focused on elephant trophy trends over 50 years in southern Africa with a report on the reduction of elephant trophy quality and more tusk-less elephants which was prevailing by the time of the report. The extent to which trophy hunting may have contributed to elephant trophy decline needs further investigation given the selectivity of this form of hunting in areas with low animal populations of some species (Damm 2008).

Coltman (2008) suggested that harvesting of wild animal populations by humans is usually targeted by sex, age or phenotypic criteria, and is therefore selective. This assertion concurs with the present study findings as only male species were legally hunted. Selective harvesting may affect wild animal population demographic structure, thus, age structure and sex ratio, which in turn may have consequences for a viable population structure and growth (Coltman 2003). Wild animals harvesting regimes that use selective criteria based on phenotypic characteristics like body size can induce artificial selection on harvested populations (Coltman 2003; Chomba et al. 2014). If there is heritable genetic variation for the target characteristic and harvesting occurs before the age of maturity, then an evolutionary response over time may ensue, in this case, decline in trophy quality could be a good indicator in that regard (Coulson et al. 2017).

Our results showed a non-significant decline in lion and leopards trophy quality over the study period in CSSA. This finding may likely be due to proper quota determination and conservation efforts in the study area. In contrast, in Tanzania, Packer et al. (2010) recorded a decline in the trophy quality of leopards and lions. It was noted that the selective removal of males of the big cats resulted in a more rapid change-over of pride males (Chomba et al. 2014). This often results in an increased rate of infanticide within the pride as each new coalition of males frequently kills the cubs that are present (Croes et al. 2011). If the rate of change of pride males takes place at intervals of less than 2 years for instance, then it is possible to have a situation where successive litters of cubs born to a pride have high risk of infanticide. Male leopards suffered particularly high mortality in Kwazulu Natal, South Africa, partly due to their higher vulnerability to trophy hunting (Balme et al. 2009). Male leopards are more desirable to trophy hunters than females because of their larger size (Bailey 2005). However, probably because of leopard's illusive behaviour (Packer et al. 2010) the hunting success was not $100 \%$ during the present study period in CSSA and this explains why their trophy quality was above the expected SCI minimum score.

Of note, the present study recorded a steady increase in buffalo trophy quality from 2009 to 2012 . The population of buffalos in CSSA between the year 2009 and 2012 were reportedly increasing with a population growth rate of
28.4\% (ZPWMA 2013). Palazy et al. (2012) suggested that a population with a steady age and sex structure has greater recruitment potential and growth. This can also translate to wild animals of good trophy quality which is perceived to be the contributing factor towards the recorded positive and improving buffalo trophy quality trend in CSSA during the period 2009-2012. However, these findings were contrary to the findings of Wilfred (2010) who noted a decline of the buffalo, Greater kudu (Tragelaphus strepsiceros), impala (Aepyceros melampus), and warthog (Phacochoerus africanus) in Ugalla wildlife area in Tanzania. Also, a study by von Brandis and Reilly (2008) observed a non-significant variation with a gentle decline in buffalo trophy in South Africa. This downward trend in the buffalo trophy quality in the southern Africa cases was reported to be associated with intensive offtake and illegal bush meat hunting (von Brandis and Reilly 2008; Wilfred 2010).

Given that three of the studied four species in CSSA recorded trophy quality below the SCI minimum score, a different proposition is that it may be premature to conclude that the observed trophy sizes were due to trophy hunting. This could be the case since most studies report that there is a global species population decline (Bonebrake et al. 2010; Chomba et al. 2014; Vignieri 2019) and there is reduced body size and animal development due to the reduced nutritive value of forage and also habitat fragmentation leading to intense inter and intra-specific competition (Coltman 2003; Ramanzin and Sturaro 2014). Thus, the SCI scoring standards which were set in 1988 might need to be revised such that they conform and adapt to the evolutionary traits of the prevailing species generation. This argument can explain the present study finding of relatively low hunting effort with reference to buffalo but low SCI trophy quality, implying that, despite the high animal encounter rate the quality of trophies remain below the SCI minimum score which were set over thirty years ago.

The study recorded no statistically significant difference in the hunting effort among the four study species between 2009 and 2012. Lindsey et al. (2006) reported that an increase in hunting effort is an indicator of the state of sustainability of the hunting activities. Thus, high hunting effort implies low animal population and lack of quality trophies. There was however a contradiction to the norm where in leopards there was a higher mean hunting effort, but the trophy quality was above the minimum score. However, most of the study species whose quotas were successfully realised in CSSA had below minimum SCI trophy quality sizes. This is a cause for concern as it highlights that most of the study species were removed when not big enough to yield a trophy quality consistent with the SCI minimum scores (Caro 2006). Thus, the monitoring of harvested populations and trophy quality trends is a crucial component in animal ecology and wildlife conservation because such measures help 
to avoid overutilization of wildlife ensuring sustainability of trophy hunting, while retaining incentives for the conservation of these wild animals and their habitats (Hutton and Leader-Williams 2003).

The study results recorded that the professional hunters' responses were consistent with the empirical data for CSSA. For instance, professional hunters reported that there was a decline in elephant trophy quality and that there was high hunting pressure in CSSA, and this concurs with the results derived through the empirical and statistical analysis of variables of the present study, thus, confirming that, in cases of scarce environmental or conservation data, other sources of information like local ecological knowledge (LEK) can be used to complement empirical evidence for conservation decisions. By regularly interacting with their local environment, the professional hunters amass LEK that can be used to inform management decisions and can serve as a useful complementary data source (Gilchrist et al. 2005; Gandiwa et al. 2014b).

\section{Conclusions}

The study assessed whether the hunting systems in CSSA were sustainable by analysing the trophy quality patterns and hunting effort for the buffalo, elephant, leopard and lion for the period 2009-2012. The study results recorded a trophy size-based quality decline in only elephant from 2009 to 2012, with buffalo, leopard and lions which recorded no decline in trophy quality during the same period. The study concluded that there was intensive harvesting of elephants as one of the four big game species in CSSA over the study period. However, arguments advanced from professional hunters generally justified trophy hunting in CSSA on the grounds that it was indispensable to conservation success and positively contribute to the local economy. Given the recorded downward trend in trophy size-based quality of elephants in CSSA, it is recommended for CSSA management to regularly review trophy hunting practices and take measures to ensure sustainable harvesting of all trophy animals.

Acknowledgements We are indebted to Zimbabwe Parks and Wildlife Management Authority for permission to conduct this study and the CSSA staff for logistical support.

\section{References}

Aronson J (1995) A pragmatic view of thematic analysis. Qual Rep $2: 1-3$

Bailey TN (2005) The African Leopard: ecology and behaviour of a solitary felid, 2nd edition. The Blackburn Press, Caldwell

Balme GA, Hunter LTB, Goodman P, Ferguson H, Craigie J, Slotow $\mathrm{R}$ (2010) An adaptive management approach to trophy hunting of leopards: a case study from KwaZulu-Natal, South Africa. In: Macdonald DW, Loveridge AJ (eds) In Biology and conservation of wild felids. Oxford University Press, Oxford, pp 341-352

Balme G, Hunter ALTB, Slotow R (2009) The impact of conservation interventions on the dynamics and persistence of a persecuted leopard population. Biol Cons 142:2681-2690

Batavia C, Nelson MP, Darimont CT, Paquet PC, Ripple WJ, Wallach AD (2019) The elephant (head) in the room: a critical look at trophy hunting. Conserv Lett 12:e12565

Bonebrake T, Christensen J, Boggs CL, Ehrlich PR (2010) Population decline assessment, historical baselines, and conservation. Conserv Lett 3(6):371-378

Bothma J, Bothma MD (2006) Leopard range size and conservation area size in the southern Kalahari. Koedoe (54): 1-160

Caro T, Andimile M (2009) Does Tanzania have a bushmeat Crisis? Miombo News1 33:7-9

Caro T (2006) Rolf Baldus Interviews Tim Caro, Professor, Dept. of Wildlife, Fish and Conservation Biology. University of California. African, Conservation Forums

Chomba C, Senzota B, Chabwela HV, Nyirenda V (2014) Lion hunting and trophy quality records in Zambia for the period 1967-2000: will the trends in trophy size drop as lion population declines? Open J Ecol 4:182-195

Coltman DW (2008) Molecular ecological approaches to studying the evolutionary impact of selective harvesting in wildlife. Mol Ecol 17(1):221-235

Coltman DW, O'Donoghue P, Jorgenson JT, Hogg CC, Strobeck M $\&$ M. Festa-Bianchet. 2003. Undesirable evolutionary consequences of trophy hunting. Nature 426: 655-657

Coulson T, Schindler S, Traill L, Kendall BE (2017) Predicting the evolutionary consequences of trophy hunting on a quantitative trait. J Wildl Manag 42(1):46-56. https://doi.org/10.1002/ jwmg.21261

Croes BM, Funston PJ, Rasmussen G, Buij R, A Saleh \& Deiongh HH (2011) The impact of trophy hunting onlions (Panthera leo) and other large carnivores in the Benoue Complex, northern Cameroon. Biol Cons 144:3064-3072

Crosmary WG, Loveridge AJ, Ndaimani H, Lebel S, Booth V, Côté. SD, Fritz H (2013) Trophy hunting in Africa: long-term trends in antelope horn size. Anim Conserv 16:648-660

Damm GR (2008) Recreational trophy hunting: what do we know and what should we do? Best practices in sustainable hunting. ftp://ftp.fao.org/docrep/fao/010/aj114e/aj 114e01.pdf

Dube N (2019) Voices from the village on trophy hunting in Hwange district, Zimbabwe. Ecol Econ 159:335-343

Dunham KM (1991) Phenology of Acacia albida trees in Zambezi riverine woodlands. Afr J Ecol 29(2):118-129

Frost PGH, Bond I (2008) The CAMPFIRE programme in Zimbabwe: payments for wildlife services. Ecol Econ 65(4):776-787

Funston PJ (2011) Population characteristics of lions (Panthera leo) in the Kgalagadi Transfrontier Park. S Afr J Wildli Resour 41:1-12

Gandiwa E, Heitk“onig IMA, Lokhorst AM, Prins HHT, Leeuwis C (2013) CAMPFIRE and human-wildlife conflicts in local communities bordering northern Gonarezhou National Park, Zimbabwe. Ecol Soc 18(4):article 7

Gandiwa E, Zisadza-Gandiwa P, Mango L, Jakarasi J (2014) Law enforcement staff perceptions of illegal hunting and wildlife conservation in Gonarezhou National Park, southeastern Zimbabwe. Trop Ecol 55:119-128

Gandiwa E, Zisadza-Gandiwa P, Muboko N, Libombo NE, Mashapa C, Gwazani R, Gandiwa E (2014) Local people's knowledge and perceptions of wildlife conservation in south eastern Zimbabwe. J Environ Protect 5:474-485

Gilchrist G, Mallory M, Merkel F (2005) Can local ecological knowledge contribute to wildlife management? Case studies of 
migratory birds. Ecol Soc 10(1):20. http://www.ecologyandsocie ty.org/vol10/iss1/art20/ [online] URL:

Grant T (2012) Leopard population density, home range size and movement patterns in a mixed landuse area of the Mangwe District of Zimbabwe. M.Sc. Thesis. Rhodes University

Groom RJ, Harris S (2009) Conservation on community lands; the importance of equitable revenue sharing. Environ Conserv $35(3): 242-251$

Hsiao T (2020) A moral defense of trophy hunting. Sport Ethics Philos 14(1):26-34. https://doi.org/10.1080/17511321.2018.1515976

Hutton JM, Leader-Williams N (2003) Sustainable use and incentivedriven conservation: realigning human and conservation interests. Oryx 37:215-226

Hyde MA, Wurstein BT, Ballings P, Coates Palgrave M (2015) Flora of Zimbabwe. Accessed July 2019. http://www.zimbabweflora.co.zw

IUCN (2012) Guiding principles on Trophy Hunting as a tool for creating conservation incentives. IUCN, Gland

Jeke A, Chanyandura A, Muposhi VK, Madhlamoto D, Gandiwa E (2019) Trophy hunting and possible source-sink dynamics in protected areas: insights from trophy size and offtake patterns in Southeast Zimbabwe. Int J Zool 1313927:9 pages. https://doi. org/10.1155/2019/1313927

Kuvawoga PT, Gandiwa E (2011) Aerial survey of elephants and other large herbivores in Chewore Safari Area, Zambezi Valley, Zimbabwe. Zimbabwe Parks and Wildlife Management Authority, Harare

Lindsey PA (2010) The future of wildlife-based land uses in Botswana. Curr Conserv 3:23-24

Lindsey PA, Alexander R, Frank LG, Mathieson A, Romanach SS (2006) Potential of trophy hunting to create incentives for wildlife conservation in Africa where alternative wildlife-based land uses may not be viable. Anim Conserv 9(3):283-291

MacDonald KI (2005) Global hunting grounds: power, scale and ecology in the negotiation of conservation. Cult Geogr 12(3):259-291

Mhuriro-Mashapa P, Mwakiwa E, Mashapa C (2018) Socio-economic impact of human-wildlife conflicts on agriculture-based livelihood in the periphery of Save Valley Conservancy, southern Zimbabwe. J Anim Plant Sci 28(3):903-914

Muboko N, Murindagomo F (2014) Wildlife control, access and utilisation: Lessons from legislation, policy evolution and implementation in Zimbabwe. J Nat Conserv 22(3):206-211

Muposhi VK, Gandiwa E, Makuza SM, Bartels P (2016) Trophy hunting and perceived risk in closed ecosystems: flight behaviour of three gregarious African ungulates in a semi-arid tropical savanna. Austral Ecol 41(7):809-818

Mysterud A (2011) Selective harvesting of large mammals: how often does it result in directional selection? J Appl Ecol 48:827-834
Naidoo R, Weaver LC, Diggle RW, Matongo G, Stuart-Hill G, Thouless C (2016) Complementary benefits of tourism and hunting to communal conservancies in Namibia. Conserv Biol 30(3):628-638

Nuzzo MC, Traill LW (2013) What 50 years of trophy records illustrate for hunted African elephant and bovid populations. Afr J Ecol 52(2):250-253

Packer C, Brink H, Kissui BM, Maliti H, Kushnir H, Caro T (2010) Effects of trophy hunting on lion and leopard populations in Tanzania. Coserv Biol 25:142-153

Palazy L, Bonenfant C, Gaillard JM, Courchamp F (2012) Rarity, trophy hunting and ungulates. Anim Conserv 15:4-11

Puertas P, Bodmer C, Richard E (2004) Hunting effort as a tool for community-based wildlife management in Amazonia. In: Silvius, KM, Bodmer RE, Fragoso JMV (eds) People in Nature: wildlife conservation in South and Central America. Columbia University Press, New York, pp 123-135. ISBN 978-0-231-12783-7

Ramanzin M, Sturaro E (2014) Habitat quality influences relative antler size and hunters' selectivity in roe deer. Eur J Wildli Resour 60:1-10

Rist L, Feintrenie L, Levang P (2010) The livelihood impacts of oil palm: smallholders in Indonesia. Biodivers Conserv 19(4):10091024. https://doi.org/10.1007/s10531-010-9815-z

Rivrud IM, Sonkoly K, Lehoczki R, Csanyi S, Storvik GO, Mysterud A (2013) Hunter selection and long-term trend (1881-2008) of red deer trophy sizes in Hungary. J Appl Ecol 50:168-180

Saayman M, van der Merwe P, Saayman A (2018) The economic impact of trophy hunting in the south African wildlife industry. Glob Ecol Conserv 16:e00510

Safari Club International (1988) Trophy hunting and the Safari Club International. Humane Society of the United States. www.bantr ophyhuntingltd.com/safari-club-international

StatSoft (2010) STATISTICA for Windows, version 10, StatSoft Inc., 2300 Tulsa.

Vignieri S (2019) Hunting and population decline. Science 363(6432):1188-1189

von Brandis RG, Reilly BK (2008) Spatial variation in trophy quality of popular hunted ungulate species in South Africa. S Afr J Wildl Res 38(1):17-21

Wilfred P (2010) Towards sustainable Wildlife Management Areas in Tanzania. Trop Conserv Sci 3(1):103-116

ZPWMA (Zimbabwe Parks and Wildlife Management Authority) (2013) Mana Pools National Park General Management Plan (2011-2021). Zimbabwe Parks and Wildlife Management Authority, Harare 